\title{
Fluoroscopically Guided Facet Injections: Comparison of Intra-Articular and Periarticular Steroid and Anesthetic Injection on Immediate and Short-Term Pain Relief
}

\author{
(D).M. Kershen, (D) N.C. Nacey, (D).T. Patrie, and (D) M.G. Fox
}

\begin{abstract}
BACKGROUND AND PURPOSE: The effectiveness of facet injections is unclear in the literature. Our objective was to determine the immediate and short-term efficacy of intra-articular and periarticular steroid/anesthetic injections for facet-mediated lumbar pain.

MATERIALS AND METHODS: All outpatient fluoroscopically guided facet injections at a single institution during a 54-month period were retrospectively and independently reviewed by 2 musculoskeletal (MSK) trained radiologists. All intra-articular, all periarticular, and partial intra-/periarticular injection locations were determined. Periarticular and partial peri-/intra-articular injections were combined for analysis. Preinjection, immediate, and 1-week postinjection numeric pain scores, patient age, sex, anesthetic/steroid mixture, fluoroscopic time, and physician performing the procedure were recorded.
\end{abstract}

RESULTS: Seventy-seven patients (mean age, 51.1 years) had 100 procedures with 205 total facet joints injected. All intra-articular, all periarticular, and partial peri-/intra-articular injections constituted $54 \%, 20 \%$, and $26 \%$ of the cases, respectively. The immediate and 1 -week postprocedural change in pain was $-3.7(95 \% \mathrm{Cl},-4.5$ to $-2.8 ; P<.001)$ and $-1.4(95 \% \mathrm{Cl},-2.2$ to $-0.6 ; P=.001)$ for the all intra-articular and $-3.6(95 \% \mathrm{Cl},-4.4$ to $-2.9 ; P<.001)$ and $-1.2(95 \% \mathrm{Cl},-1.9$ to $-0.4 ; P=.002)$ for the combined group. Changes in immediate pain were significantly associated with the prepain level $(P<.001)$ and patient age $(P=.024)$ but not with the anesthetic used. Analyses revealed no significant difference in pain reduction between the groups either immediately or 1 week postinjection. Intra-articular injections required less fluoroscopic time (geometric mean, 39 versus 52 seconds) $(P=.005)$.

CONCLUSIONS: Intra-articular and periarticular fluoroscopically guided facet injections provide statistically significant and similar pain relief both immediately and 1 week postinjection.

G iven the variety of presentations and factors that contribute to low back pain, determining the optimal treatment method may be challenging. The facet joint is 1 possible etiology of axial low back pain with both surgical and nonsurgical treatment methods used to provide pain relief. ${ }^{1}$ Facet-mediated pain or "facet syndrome" may account for up to $45 \%$ of

Received March 27, 2018; accepted after revision July 30.

From the Colorado Imaging Associates (L.M.K.), Golden, Colorado; Departments of Radiology and Medical Imaging (N.C.N.) and Public Health Sciences (J.T.P.), University of Virginia, Charlottesville Virginia; and Department of Radiology (M.G.F.), Mayo Clinic Arizona, Phoenix, Arizona. Drs. Fox and Kershen were previously affiliated with the Department of Radiology and Medical Imaging, University of Virginia, Charlottesville, Virginia.

Previously presented as an electronic scientific exhibit (O-476) at: Annual Meeting of the American Society of Neuroradiology and the Foundation of the ASNR Symposium, April 25-30, 2015; Chicago, Illinois.

Please address correspondence to Michael G. Fox, MD, MBA, Mayo Clinic Arizona, Department of Radiology, 5777 E Mayo Blvd, Phoenix, AZ 85054; e-mail:

Fox.Michael@mayo.edu

http://dx.doi.org/10.3174/ajnr.A5805 cases of axial low back pain. ${ }^{2}$ The characteristic pain in facet syndrome is located in the low back with involvement of the buttock/greater trochanteric region with occasional unilateral extension along the lateral thigh. ${ }^{1,2}$ The pain is usually more pronounced after immobilization and with low back extension. ${ }^{2}$ The injection of a local anesthetic is often used to both diagnose and manage facet-mediated pain. ${ }^{1,2}$ Even though there is a paucity of literature to support the use of intraarticular steroid injections in this patient population, corticosteroids are often injected to provide longer term pain relief and restore functional status. ${ }^{3-12}$ Whether intra-articular or periarticular placement of the injectate substantially alters the efficacy of the injection is also debated. ${ }^{4,7,8}$ Therefore, we retrospectively evaluated patients with fluoroscopically guided facet injections for clinically suspected facet syndrome to determine the immediate and short-term efficacy of those injections and to evaluate whether an intra-articular or periarticular injection provided greater pain relief. 


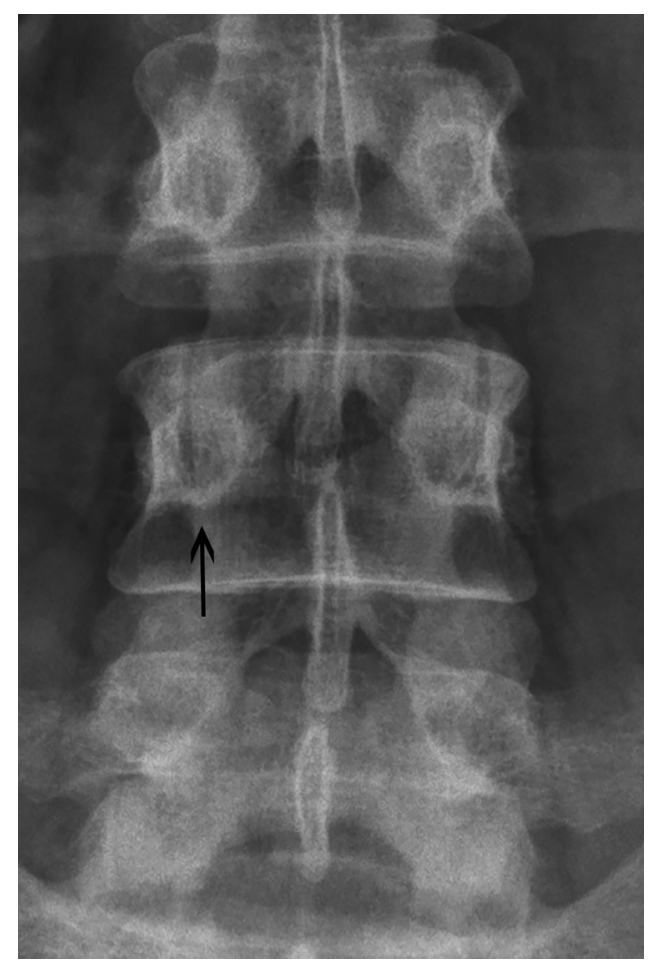

FIG 1. Anteroposterior image of the lumbar spine demonstrates the straight anteroposterior approach to accessing the inferior articular recess (arrow) of the facet joint.

\section{MATERIALS AND METHODS}

Institutional review board approval was obtained from The University of Virginia for the study. All outpatient fluoroscopically guided facet injections performed during a 4-year period (June 2010 to October 2014) at a single institution were retrospectively reviewed. More than $90 \%$ of the patients were referred by orthopedic spine specialists $(n=94)$ for treatment of suspected facet syndrome or to help quantify the degree of back pain accounted for by the facet arthropathy; physical medicine and rehabilitation $(n=4)$ and neurosurgery $(n=2)$ accounted for the remainder of the patient referrals.

\section{Technique}

After we obtained written informed consent, the patients were placed prone on the fluoroscopic table with a bolster placed under their lower abdomen to reduce lordosis. The patients were sterilely prepped and draped in the usual manner and a 22-ga 3.5-inch spinal needle was directed toward the inferior articular recess of the facet joint using fluoroscopic guidance (Fig 1). ${ }^{13}$ Following needle placement, 0.5-1 mL of iohexol (Omnipaque 300) was injected to confirm placement. Opacification of the facet joint and/or superior articular recess was used as the criterion for determining an intra-articular injection (Fig 2). When contrast was not demonstrated in the facet joint, the injection was considered periarticular (Fig 3). The patients were then injected with either $0.5 \mathrm{~mL}$ of $0.25 \%$ bupivacaine ( $n=29$ procedures); $0.5 \mathrm{~mL}$ of $0.5 \%$ bupivacaine ( $n=39$ procedures); or $0.5 \mathrm{~mL}$ of $1 \%$ lidocaine $(n=$ 32 procedures $)$ and either $20 \mathrm{mg}(0.5 \mathrm{~mL})$ of methylprednisolone acetate (Depo-Medrol) ( $n=92$ procedures), $3 \mathrm{mg}(0.5 \mathrm{~mL})$ of betamethasone (Celestone) ( $n=4$ procedures), or $20 \mathrm{mg}(0.5$

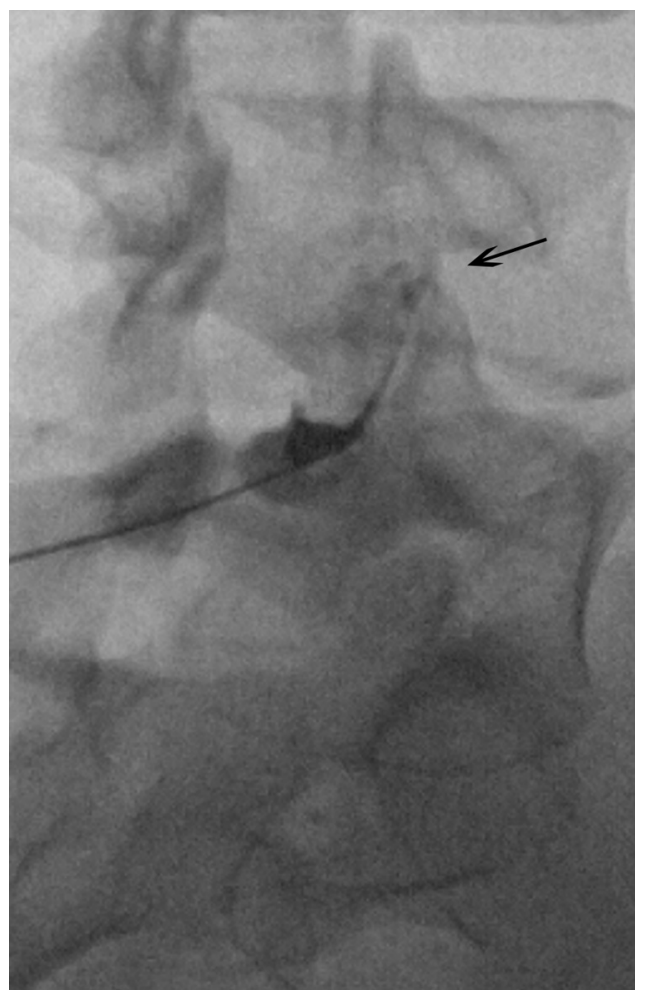

FIG 2. Oblique fluoroscopic image of the L4-L5 facet joint demonstrates an intra-articular injection. Contrast spreads from the injection into the inferior recess to the superior recess (arrow).

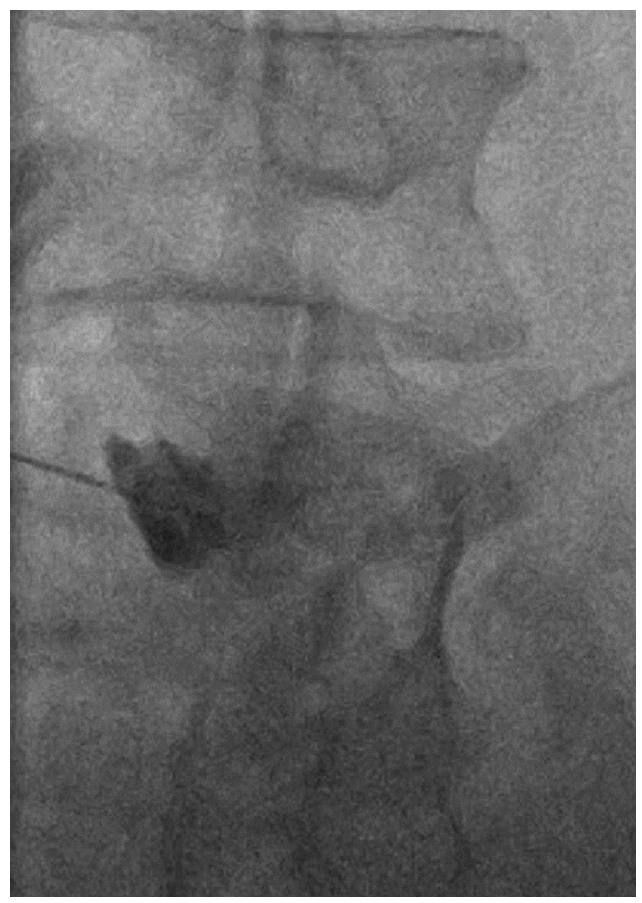

FIG 3. Oblique fluoroscopic image of the L4-L5 facet joint demonstrates a periarticular injection. Contrast pools around the needle tip adjacent to the hypertrophied facet joint. No contrast is identified within the joint or joint recess.

$\mathrm{mL}$ ) of triamcinolone acetonide (Kenalog) ( $n=4$ procedures). The injection was performed by either a musculoskeletal (MSK) fellow $(n=30)$, an MSK faculty member $(n=2)$, or an MSK fellow with an MSK faculty member present $(n=68)$. 


\section{Pain Analysis}

All patients reported their preinjection and 5- to 10-minute postinjection pain scores to a radiology nurse using an 11-point Numeric Pain Rating Scale; 0 (no pain) to 10 (worst pain imaginable). In addition, patients were called 1 week postinjection, and the current pain score was recorded using the same 11-point scale. We were able to record a 1-week pain score for 49\% (49/100) of the procedures. Patients were excluded if a different concentration of steroid was injected, if a preinjection or 5- to 10-minute postinjection pain score was not recorded, or if a pars defect was present. Patients younger than 16 years of age were also excluded from the study.

\section{Image Analysis}

Two fellowship-trained MSK radiologists, with 2 and 16 years of experience in performing facet injections, independently reviewed the fluoroscopic images to determine whether the injections were intra-articular or periarticular. When a discrepancy was present, the discrepant cases were re-analyzed in a blinded fashion and a consensus interpretation was rendered. The consensus interpretation was used for the statistical analyses. If an injection of $>1$ facet joint was performed in the same setting, all injections needed to be within the facet joint for the injection to be considered "all-in." Likewise, all the injected facet joints needed to be periarticular to be considered "all-out." When bilateral or 2-level facet injections were performed, if $\geq 1$ of the injections was determined to be periarticular and $\geq 1$, intra-articular, the injection was considered "partial." Partial and all-out groups were combined for analysis.

\section{Statistical Analysis}

Data Summary. Categoric data were summarized as frequencies and percentages, and continuous scaled data were generally summarized by the mean and SD of the distribution.

Interreader Agreement. The concordance between the 2 readers' assessments of whether the intra-articular injection was "all-in", partially in, or "all-out" was evaluated by the $\kappa$ statistic. An exact binomial confidence interval was used to establish a plausible range of values for the underlying level of concordance between the 2 readers' injection classifications.

\section{Postprocedure Pain Analysis}

ANCOVA models were used to estimate the immediate and shortterm postinjection mean changes in the pain scores. The ANCOVA model for examining the immediate change in pain was specified so that the partial variability in the immediate change in pain attributable to the injection site ("all-in" versus "partially in" or "all-out") and the partial variability in the immediate change in pain attributable to the anesthetic type $(0.5 \mathrm{~mL}$ of $0.25 \%$ bupivacaine, $0.5 \mathrm{~mL}$ of $0.50 \%$ bupivacaine, or $0.5 \mathrm{~mL}$ of $1 \%$ lidocaine) could be examined after accounting for the variabilities in immediate change in pain attributable to patient age, sex, prepain level, and procedure personnel (attending physician involvement). The ANCOVA model for examining short-term (1 week postinjection) change in pain was specified in the same way as the ANCOVA model for the immediate change in pain, except that the "anesthetic type" was excluded. All null hypotheses related to the immediate and short-term changes in pain were tested via $F$ tests, and a $P<.05$ decision rule was used as the null hypothesis rejection rule.

\section{Fluoroscopic Time}

Fluoroscopic time was analyzed on the natural logarithmic scale via ANCOVA, with the injection location the ANCOVA model factor of interest, and the personnel preforming the procedure as the ANCOVA covariates. Comparison of fluoroscopic time was with the geometric mean fluoroscopic time, and a $P<.05$ decision rule was used for testing the null hypothesis that the geometric mean ratio is equal to 1 .

\section{Statistical Software}

The statistical software package SAS, Version 9.4 (SAS Institute, Cary, North Carolina) was used to conduct the aforementioned statistical analyses.

\section{RESULTS}

One hundred procedures were performed on 77 patients (29 males, 48 females; mean age, 51.1 years; range, $16-67$ years) with a total of 205 facet joints injected. Sixty-six patients underwent 1 procedure, 8 patients underwent 2 procedures, and 1 patient each underwent 3, 4, and 11 procedures. Twenty-four procedures (24\%, 24 facets) were single-facet injections, 61 (61\%, 122 facets) procedures were 2 -facet injections in the same sitting, 1 procedure had 3 facet injections (1\%, 3 facets), and 14 (14\%, 56 facets) procedures had 4 facets injected in the same sitting. We injected the following facet levels: T12-L1 $(n=4), \mathrm{L} 1-\mathrm{L} 2(n=2), \mathrm{L} 2-\mathrm{L} 3(n=$ 9), L3-L4 $(n=20)$, L4-L5 $(n=104)$, and L5-S1 $(n=66)$.

The consensus interpretation in 54 of 100 procedures (100/ 205 facets injected) was all intra-articular; in 20 procedures (33/ 205 facets), it was all periarticular; and in 26 procedures (72/205 facets), it was partial intra-articular injection. Exact agreement between the 2 readers was present in 77\% (77/100) (95\% CI, $0.68-0.84)$ of the procedures with a $\kappa$ statistic of $0.60(95 \% \mathrm{CI}$, $0.46-0.75)$.

Analysis of the immediate (5- to 10-minute) change in pain yielded a statistically significant association with the prepain level $(P<.001)$ and patient age $(P=.024)$ (older patients experienced greater pain relief) but no significant association with the anesthetic used $(P=.431)$, sex $(P=.205)$, or the radiology team member performing the procedure $(P=.153)$. Analysis of the 1 -week change in pain revealed no statistically significant association with the prepain level $(P=.979)$, patient age $(P=.462)$, sex $(P=.979)$, or the radiology team member performing the procedure $(P=.672)$.

The mean preinjection and 5- to 10-minute postinjection pain scores for the 54 procedures in the all intra-articular group were 6.3 and 2.7, respectively, with a mean change in pain of $-3.7(95 \%$ $\mathrm{CI},-4.5$ to $-2.8 ; P<.001)$. The mean preinjection and 5 - to 10 -minute postinjection pain scores for the 46 periarticular/partial procedures were 5.8 and 2.1, respectively, with a mean change in pain of $-3.6(95 \% \mathrm{CI},-4.4$ to $-2.9 ; P<.001)$ (Table 1$)$.

Twenty-four of the all intra-articular injections had a 1-week postprocedure pain score recorded with the mean 1-week postin- 
Table 1: Mean pain level in the 5- to 10-minute postinjection period when accounting for intra-articular-versus-periarticular/partial injections

\begin{tabular}{lccccc}
\hline & No. & Prepain & Postpain & $\begin{array}{c}\text { Change in } \\
\text { Pain }(95 \% \mathrm{Cl})\end{array}$ & $\begin{array}{c}\text { P Value } \\
\text { (Unadjusted) }\end{array}$ \\
\hline All-in & 54 & 6.3 & 2.7 & $-3.7(-4.5$ to -2.8$)$ & $<.001$ \\
All-out/partial & 46 & 5.8 & 2.1 & $-3.6(-4.4$ to -2.9$)$ & $<.001$ \\
\hline
\end{tabular}

Table 2: Mean pain level 1 week postinjection when accounting for intra-articular-versusperiarticular/partial injections

\begin{tabular}{lccccc}
\hline & No. & Prepain & Postpain & $\begin{array}{c}\text { Change in } \\
\text { Pain }(95 \% \mathrm{Cl})\end{array}$ & $\begin{array}{c}\text { P Value } \\
\text { (Unadjusted) }\end{array}$ \\
\hline All-in & 24 & 6.4 & 5.0 & $-1.4(-2.2$ to -0.6$)$ & .001 \\
All-out/partial & 25 & 6.8 & 5.7 & $-1.2(-1.9$ to -0.4$)$ & .002 \\
\hline
\end{tabular}

Table 3: ANCOVA summary of mean change in pain between the immediate and 1-week postinjection period when adjusting for prepain level, age, sex, and radiology team member performing the procedure

\begin{tabular}{lcc}
\hline & $\begin{array}{c}\text { Difference in Mean Change } \\
\text { in Pain between All-In and } \\
\text { All-Out/Partial Groups (95\% CI) }\end{array}$ & $\begin{array}{c}\boldsymbol{P} \text { Value } \\
\text { (Adjusted) }\end{array}$ \\
\hline Immediate & $0.46(-0.56-1.49)$ & .371 \\
One week & $0.27(-0.94-1.48)$ & .652 \\
\hline
\end{tabular}

jection change in pain of $-1.4(95 \% \mathrm{CI},-2.2$ to $-0.6 ; P=.001)$. Twenty-five of the periarticular/partial injections had a 1-week postprocedural pain score recorded with a mean 1 -week postinjection change in pain of $-1.2(95 \% \mathrm{CI},-1.9$ to $-0.4 ; P=.002)$ (Table 2).

The mean difference in the change in pain 5-10 minutes postinjection between the intra-articular and periarticular/partial groups was 0.46 (95\% CI, -0.56 to $1.49 ; P=.371)$, and the mean difference in the change in pain between the intra-articular and periarticular/partial groups at 1 week postinjection was 0.27 (95\% CI, -0.94 to $1.48 ; P=.652$ ) (Table 3 ).

The mean fluoroscopic time for intra-articular, periarticular, and partial injection was 44,59, and 54 seconds, respectively. After adjusting for the person performing the injection (fellow alone, and so forth), a statistically significant difference in the ratio of geometric means between the intra-articular and periarticular/partial groups was noted (geometric mean ratio $=1.31$; 95\% CI, 1.08-1.58; $P=.005)$.

\section{DISCUSSION}

The facet joint is a known contributor to axial low back pain. However, diagnosing facet-mediated pain can be challenging due to confounding factors in pain generation such as concomitant lumbar disk and sacroiliac joint degenerative changes. In addition, dual innervation of the facet joint by medial branches of the dorsal ganglion at and above the level of the target facet may further complicate the diagnosis and treatment of facet-mediated pain.

Even though injections have been used for decades to diagnose and manage facet-mediated pain, the utility of injections to relieve this pain as reported in the literature is inconclusive. ${ }^{14}$ Local anesthetics inhibit nerve conduction and excitation to various degrees with the 3 most commonly used agents being lidocaine (shortest acting), bupivacaine, and ropivacaine (longest acting). ${ }^{15}$ It is generally accepted that anesthetic-only injections are useful as a diagnostic test for facet-mediated pain in clinically unclear cases.
Mooney and Robertson ${ }^{1}$ demonstrated that saline injected into the facet joint could reproduce facet-mediated pain and that the pain could be alleviated with a local anesthetic injection.

Corticosteroids can interrupt the inflammatory cascade, which is thought to contribute to axial back pain, ideally resulting in longer pain relief than that provided by local anesthetics. The 4 most commonly used corticosteroid agents include the following: methylprednisolone, triamcinolone, betamethasone, and dexamethasone, with only dexamethasone considered nonparticulate unless it is combined with ropivacaine, which will result in particulate formation. ${ }^{15}$ While the use of corticosteroids in back injections is generally accepted, the specific use of intra-articular steroid injections for facet-mediated pain is less clear. Mooney and Robertson ${ }^{1}$ reported that $20 \%$ of patients achieved complete and $33 \%$ of patients experienced partial pain relief 6 months following steroid injection. Similarly, Destouet et $\mathrm{al}^{3}$ determined that $54 \%$ of patients, many of whom had prior spinal surgery, responded to facet steroid injections. In fact, $38 \%$ of the responders achieved long-term (6-12 months) clinical improvement. In contrast, Lilius et $\mathrm{al}^{4}$ randomized patients into 3 facet-injection groups: steroid, anesthetic only, and normal saline. They found a significant improvement in the pain and disability scores for all 3 groups, with no significant difference among the groups. As a result, they questioned the utility of steroid and anesthetic injections for managing facet pain.

More recently, Manchikanti et al, ${ }^{5}$ using a meta-analysis, concluded that there is limited evidence to support the use of intraarticular lumbar facet steroid injections based on 3 high-quality studies demonstrating effectiveness for follow-up $<6$ months and 2 moderate to high-quality studies demonstrating a lack of effectiveness. Similarly, Bogduk ${ }^{6}$ concluded that the efficacy of intraarticular steroid injections was no better than that of sham treatments. Because there is limited evidence to support the routine use of steroid facet injections, Bykowski and Wong ${ }^{2}$ advocated a more tailored use of steroid injections, reserving them for patients in whom radiofrequency ablation was refused or contraindicated.

We found no difference in the 1-week postinjection pain relief between the all intra-articular and the combined all periarticular and partial peri-/intra-articular groups, which is similar to the results reported by Lilius et al. ${ }^{4}$ In contrast, Lynch and Taylor ${ }^{7}$ reported that intra-articular injections were substantially better than periarticular injections in relieving facet-mediated pain 2 weeks postinjection.

The imaging guidance used to perform facet injections is often based on operator familiarity and the availability of equipment. In our experience, fluoroscopically guided facet injections can be performed with minimal radiation exposure. We found that intra-articular injections required less fluoroscopic time compared with periarticular injections, which is likely because some radiologists were more diligent in attempting to access to the facet joint. When accessing the joint or joint recess was more challenging, due to facet joint degeneration and hypertrophy, some perform- 
ing radiologists were less concerned about being intra-articular because the efficacy of intra-articular compared with periarticular steroid injections remains unclear. We suspect that if a periarticular injection was the primary goal of all of the performing radiologists, the fluoroscopy time would be substantially lower in this group. Nevertheless, the mean fluoroscopic time in our study was $<60$ seconds in each group.

Our study is limited because it is retrospective and lacks a randomized control group. In addition, our 1-week response rate was only $49 \%$, which limits our patient population in this category. However, the 1-week response rate was fairly equal between the 2 groups. The lack of follow-up beyond 1 week is also a limitation.

\section{CONCLUSIONS}

Both intra-articular and periarticular facet injections provide similar and statistically significant immediate and 1-week postinjection relief of facet-mediated pain.

\section{ACKNOWLEDGMENTS}

The data for this project originated from and were provided by the University of Virginia.

\section{REFERENCES}

1. Mooney V, Robertson J. The facet syndrome. Clin Orthop Relat Res 1976;115:149-56 Medline

2. Bykowski JL, Wong WH. Role of facet joints in spine pain and image-guided treatment: a review. AJNR Am J Neuroradiol 2012;33: 1419-26 CrossRef Medline

3. Destouet JM, Gilula LA, Murphy WA, et al. Lumbar facet joint injection: indication, technique, clinical correlation, and preliminary results. Radiology 1982;145:321-25 CrossRef Medline
4. Lilius G, Laasonen EM, Myllynen P, et al. Lumbar facet joint syndrome: a randomised clinical trial. J Bone Joint Surg Br 1989;71: 681-84 Medline

5. Manchikanti L, Kaye AD, Boswell MV, et al. A systemic review and best evidence synthesis of the effectiveness of therapeutic facet joint interventions in managing chronic spinal pain. Pain Physician 2015; 18:E535-82 CrossRef Medline

6. Bogduk N. A narrative review of intra-articular corticosteroid injections for low back pain. Pain Med 2005;6:287-96 CrossRef Medline

7. Lynch MC, Taylor JF. Facet joint injection for low back pain: a clinical study. J Bone Joint Surg Br 1986;68:138-41 Medline

8. Staal JB, de Bie R, de Vet HC, et al. Injection therapy for subacute and chronic low back pain: an updated Cochrane review. Spine (Phila Pa 1976) 2009;34:49-59 CrossRef Medline

9. Carette S, Marcoux S, Truchon R, et al. A controlled trial of corticosteroid injections into facet joints for chronic low back pain. $N E n g l$ J Med 1991;325:1002-07 CrossRef Medline

10. Fuchs S, Erbe T, Fischer HL, et al. Intraarticular hyaluronic acid versus glucocorticoid injections for nonradicular pain in the lumbar spine. J Vasc Interv Radiol 2005;16:1493-98 CrossRef Medline

11. Murtagh FR. Computed tomography and fluoroscopy guided anesthesia and steroid injection in facet syndrome. Spine (Phila Pa 1976) 1988;13:686-89 CrossRef Medline

12. Lippitt $A B$. The facet joint and its role in spine pain: management with facet joint injections. Spine (Phila $\mathrm{Pa}$ 1976) 1984;9:746-50 CrossRef Medline

13. Sarazin L, Chevrot A, Pessis E, et al. Lumbar facet joint arthrography with the posterior approach. Radiographics 1999;19:93-104 CrossRef Medline

14. Vekaria R, Bhatt R, Ellard DR, et al. Intra-articular facet joint injections for low back pain: a systematic review. Eur Spine J 2016;25: 1266-81 CrossRef Medline

15. MacMahon PJ, Huang AJ, Palmer WE. Spine injectables: what is the safest cocktail? AJR Am J Roentgenol 2016;207:526-33 CrossRef Medline 